\title{
Effect of Waste Glass Powder on Phase, Microstructure and Mechanical Properties of Mullite Based Porous Ceramics with Coal-series Solid Waste as Raw Materials
}

\section{Wei Lian}

Anhui University of Science and Technology

Yan Liu

Anhui University of Science and Technology

Wenjie Wang

Anhui University of Science and Technology

Yangtao Dong

Anhui University of Science and Technology

Sheng Wang

Anhui University of Science and Technology

Zhenying Liu

Anhui University of Science and Technology

Yin Liu ( $\square$ liuyinaust@sina.com )

Anhui University of Science and Technology

\section{Research Article}

Keywords: Mullite porous ceramics, Mechanical properties, waste disposal, Gangue

DOI: https://doi.org/10.21203/rs.3.rs-25066/v1

License: (c) (i) This work is licensed under a Creative Commons Attribution 4.0 International License.

Read Full License 


\section{Abstract}

Mullite based porous ceramics were successfully prepared by using a solid-phase method with gangue, slime and sawdust as raw materials. The effects of the content of glass powder and calcining temperature on microstructure and mechanical properties of the samples were systematically studied. It is found that glass powder can prevent the formation of Kyanite and reduce the synthesis temperature of mullite. The samples with $4 \%$ glass powder have a large amount of mullite calcined at $1150^{\circ} \mathrm{C}$ for $3 \mathrm{~h}$. Meanwhile, alumina in the sample is completely converted into mullite at $1180^{\circ} \mathrm{C}$ for $3 \mathrm{~h}$. Mullite content reaches $64.2 \mathrm{wt} \%$. The minimum apparent porosity is $31.22 \%$, while the maximum volume density and diameter shrinkage are $1.74 \mathrm{~g} / \mathrm{cm} 3$ and $8.48 \%$, respectively. The ratio of pores of $<8 \mu \mathrm{m}$ to those of $8 \sim 20 \mu \mathrm{m}$ is varied from 7:2 to $2: 7$, due to the addition of the glass powder. With increasing content of mullite, the flexural properties of the samples are increased from 7.7MPa to $28.36 \mathrm{MPa}$. Therefore, with solid wastes as the resource, the porous ceramics have a bright prospect.

\section{Introduction}

Coal is a key energy source in developing countries. Coal gangue and slime are solid wastes produced in the process of coal mining and washing ${ }^{[1]}$. The main components of coal gangue are silica and alumina, which come from the extraction of roadway and the selection of coal preparation process ${ }^{[2-4]}$. Coal gangue is piled up, which causes environmental pollution and has potential safety hazards, due to possibly spontaneous combustion ${ }^{[5-7]}$. As fillers or making build materials, gangue can be used in a value-adding way. However, mechanical dispersion of coal gangue as fillers may cause environmental pollution through the leaching of heavy metal elements ${ }^{[4,5]}$. It is therefore desired to develop more effective technology for gangue utilization. The pollution of slime is higher than that of gangue due to its small particle size and chemical properties ${ }^{[8-10]}$. At the same time, the low calorific value and high ash content make the reuse of coal slime to be difficult. If they can be utilized effectively, we can solve the above pollution issue and promote the development of regional economy.

Mullite is a scarce ceramic material with various interesting properties in nature ${ }^{[11-16]}$. Mullite fiber is often used as reinforcing material of ceramics ${ }^{[17-21]}$. Mullite porous ceramics not only have high stability at high temperatures, but also are used in various situations because of their abundant pore structures ${ }^{[17}$, 18, 22-25]. Lü et al. prepared porous mullite ceramics with solid waste by using an in-situ synthesis

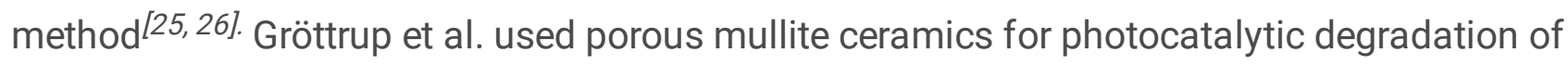
wastewater $^{[24]}$. Wang et al. fabricated mullite foams from coal-series kaolin using freeze-cast ${ }^{[22] .}$ Three dimensional mullite fiber reinforced mullite reported by Wang et al with a new method ${ }^{[27]}$. In summary, fabrication of mullite porous ceramics prepared from solid wastes is of bright prospect in industrial application and environmental remediation. However, it is still a challenge, because organic burning may cause matrix damage. 
In this study, mullite based porous ceramics were fabricated by calcining of coal gangue and slime, with sawdust as the pore agent. Meanwhile, the effect of glass powder on the properties of samples at different temperatures was studied.

\section{Experimental}

\subsection{Samples preparation}

Tab. 1 lists contents and characteristics of the raw materials. Pore structure and porosity are regulated by burning rate and particle size of the raw materials. Gangue (Huainan), slime (Huainan), sawdust, flat glass powder and $\mathrm{Na}_{2} \mathrm{CO}_{3}$ (Xuzhou reagent No.2 Factory, AR) were mixed through ball milling (XGB-04, Nanjing Boyuntong Instrument Technology Co., Ltd). Slime was viscose and used as binder together with $5 \%$ deionized water. Cylindrical green samples (diameter $95 \mathrm{~mm}$ and height $3 \mathrm{~mm}$ ) and bars green samples $\left(4 \times 4 \times 40 \mathrm{~mm}^{3}\right)$ were prepared at a pressure of $5 \mathrm{MPa}$ for $1 \mathrm{~min}$. Mechanical properties and calcining properties of the porous ceramics were studied as a function of amount of the glass powder. The samples with $0 \%, 2 \%, 4 \%$ and $6 \%$ glass powder were denoted as GP0, GP2, GP4 and GP6, respectively.

Tab.1 Contents and characteristics of the raw materials.

\begin{tabular}{cccc}
\hline Raw material & Mass percentage $(w t \%)$ & Particle size $(\mu \mathrm{m})$ & Burning loss rate $(\%)$ \\
\hline Coal Cangue & 62.50 & $<74$ & 6.74 \\
Slime & 26.80 & $<74$ & 57.46 \\
Sawdust & 8.90 & $<180$ & 97.80 \\
$\mathrm{Na}_{2} \mathrm{CO}_{3}$ & 1.80 & $/$ & $/$ \\
\hline Glass powder & $/$ & $<74$ & \\
\hline
\end{tabular}

\subsection{Calcination}

Fig. 1 shows temperature profile to calcine the samples. Green samples were calcined with a box resistance furnace(SX2, Xiangtan Huafeng Instrument Manufacturing Co., Ltd, China) in oxygen atmosphere at different temperatures $\left(1070^{\circ} \mathrm{C}, 1100^{\circ} \mathrm{C}, 1130^{\circ} \mathrm{C}, 1150^{\circ} \mathrm{C}\right.$ and $\left.1180^{\circ} \mathrm{C}\right)$ for $3 \mathrm{~h}$. Firstly, the green were samples heated from room temperature to $500^{\circ} \mathrm{C}$ at the rate of $5^{\circ} \mathrm{C} / \mathrm{min}$ and kept at $500^{\circ} \mathrm{C}$ for $1 \mathrm{~h}$ to decompose organic phases. Then, the temperature was increased to $1000^{\circ} \mathrm{C}$ at a heating rate of $3^{\circ} \mathrm{C} / \mathrm{min}$. In this process, the glass powder was molten. Mechanical properties of the samples were improved due to the presence of the continuous matrix, while the sample were densified. Finally, the 
temperature was increased to final temperatures at slowly at a heating rate of $1{ }^{\circ} \mathrm{C} / \mathrm{min}$ and calcined for 3h. At this stage, Mechanical properties were further improved owing to the formation of mullite.

\subsection{Characterization}

Phase compositions of the samples were studied by using X-ray diffractometer (XRD, SmartLab, Rigaku Corporation, Japan). RIR-quantitative analysis was used to calculate the phase content with the XRD

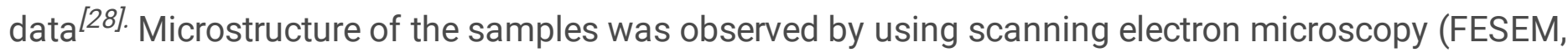
Sigma 300, Zeiss, Germany). Archimedes method was used to measure density and apparent porosity of the samples. Diameters of the samples before and after calcination were used to calculate the diameter shrinkage (D) by using the following equation $(1)^{[29,30] \text { : }}$

$$
D=\frac{d_{0}-d}{d_{0}} \times 100 \%
$$

where $d_{0}$ and $d$ are the sample diameters $(\mathrm{mm})$ before and after calcination, respectively.

Pore size distribution of the samples was measured by suing a pore size analysis instrument. Flexural strength of the samples was tested by using the three-point bending method with GB/T 1965-1996. The breaking force of each group is the average value of five samples broken by using universal testing machine (WDW-50, Shenzhen Kaiqiangli Test Instrument Co., Ltd, China). The flexural strengths were

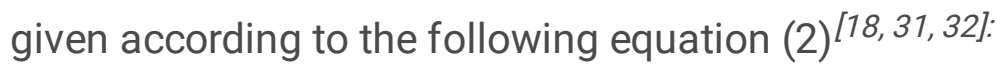

$$
F=\frac{3 l f}{2 b h^{2}}
$$

where $F$ is the flexural strength $(\mathrm{MPa}), \mathrm{I}$ is the span $(\mathrm{mm})$ between the sample and the mold, $f$ is the maximum stress $(\mathrm{N})$ of the samples, $b$ and $h$ are the width $(\mathrm{mm})$ and height $(\mathrm{mm})$ of the sample, respectively.

\section{Results And Discussion 3.1. Phase analysis}

Fig. 2 shows XRD patterns of the raw materials. The gangue kaolinite $\left(\mathrm{Al}_{2}\left(\mathrm{Si}_{2} \mathrm{O}_{5}\right)\left(\mathrm{OH}_{4}\right), \mathrm{PDF} \# 73-1996\right)$ and quartz $\left(\mathrm{SiO}_{2}, \mathrm{PDF} \# 89-1961\right)$ as the main phases. The slime indicates also contained kaolinite $\left(\mathrm{Al}_{2}\left(\mathrm{Si}_{2} \mathrm{O}_{5}\right)\left(\mathrm{OH}_{4}\right), \mathrm{PDF} \# 80-0886\right)$ and quartz $\left(\mathrm{SiO}_{2}, \mathrm{PDF} \# 86-2237\right)$ as the major crystalline phases ${ }^{[21,24]}$. Organic matter and minor unknown matters are also observed in the slime, as demonstrated by the peaks 
at $20^{\circ} \sim 30^{\circ}$ and $29.5^{\circ}$. Organic and unknown matter were not studied because they were decomposed at high temperatures ${ }^{[15,26,33]}$.

Fig. 3 shows XRD patterns of two groups of samples calcined at different temperatures. Mullite $\left(\mathrm{Al}_{4.52} \mathrm{Si}_{1.48} \mathrm{O}_{9.74}, \mathrm{PDF} \# 79-1457\right)$ and quartz $\left(\mathrm{SiO}_{2}, \mathrm{PDF} \# 85-0930\right)$ are the main crystal phases in the samples. For the samples without the addition of the glass powder, mullite content is obviously changed with calcination temperature. Kyanite ( $\left.\mathrm{Al}_{2} \mathrm{SiO}, \mathrm{PDF} \# 83-1569\right)$ was detected at $1130^{\circ} \mathrm{C}$ but absent at $1180^{\circ} \mathrm{C}^{[34]}$. In the samples with $4 \%$ glass powder, kyanite was not present, while a rapid increase in the content of mullite was observed at $1180^{\circ} \mathrm{C}$. It indicates that the addition of glass powder can suppress the formation of kyanite, promote the synthesis of mullite and reduce the calcining temperature. This is because the liquid phase from the glass powder at high temperatures can promote the densification of the samples.

Fig. 4 shows representative XRD patterns and phase content of the samples calcined at $1180^{\circ} \mathrm{C}$ for $3 \mathrm{~h}$. The content of mullite is increased gradually, while that of quartz is decreased, as the content of glass powder is increased to $4 \%$. Above $4 \%$, the content of quartz is slightly increased. Correspondingly, the content of mullite is decreased. In other words, the highest mullite content is $64.2 \%$ in the sample with $4 \%$ glass powder. In other words, $4 \%$ glass powder is optimal for mullite formation.

\subsection{Microstructure}

Fig. 5 depicts SEM images of GPO and GP4 calcined at different temperatures. After calcining at $1070^{\circ} \mathrm{C}$ for $3 \mathrm{~h}$, the sample is not densified, with small and uniform pores. The pore size is increased with increasing calcination temperature, because mullite is formed due to the reaction of the raw materials. Obvious crystallization is observed after calcining at $1180^{\circ} \mathrm{C}$. The surface of GP4 is smoother than that of GPO after calcining at $1070^{\circ} \mathrm{C}$. A large number of rod-like crystals are present in GP4 calcined $1130^{\circ} \mathrm{Cand}$ the matrix is denser at $1180^{\circ} \mathrm{C}$. It is believed that the liquid phase derived from the glass powder promoted the formation and growth of mullite.

Fig. 6 shows cross-sectional SEM images of the samples with different contents of glass calcined at $1180^{\circ} \mathrm{C}$ for $3 \mathrm{~h}$. There are grains on the surface of GP0, while interlaced rod crystals and broken crystals are observed on the fracture surface and inside the holes of GP2, GP4 and GP6. The interlaced mullite in the matrix would improve flexural properties of the samples ${ }^{[31]}$. Large holes and small pits are present on the fracture surface of GP6, as shown in Fig. 6(d). It means that the sample contains closed pores, which are formed because of the interaction between the melting glass and the raw materials.

\subsection{Archimedes method and linear shrinkage}

Fig. 7 displays apparent porosity, density and diameter shrinkage of GPO calcined between $1070^{\circ} \mathrm{C}$ and $1180^{\circ} \mathrm{C}$. The apparent porosity is more than $40.92 \%$, whereas the density and linear shrinkage are less 
than $1.50 \mathrm{~g} / \mathrm{cm}^{3}$ and $9.27 \%$, respectively. This suggests that the sample without glass powder has not reacted completely at $1180^{\circ} \mathrm{C}$. This observation is consistent with the results of XRD and SEM.

Fig. 8 shows the apparent porosity, density and linear shrinkage of GP2, GP4 and GP6 with calcination temperature. The apparent porosity is decreased, while both the density and diameter shrinkage are increased, with increasing calcination temperature. Therefore, the content of glass powder affects all the apparent porosity, bulk density and diameter shrinkage of the samples. At a given calcination temperature, the apparent porosity is decreased, while the density and diameter shrinkage are increased with increasing content of glass powder. For example, after calcining at $1180^{\circ} \mathrm{C}$, the apparent porosities are $42.59 \%, 34.62 \%, 33.15 \%$ and $31.22 \%$, for GP0, GP2, GP4 and GP6, respectively. The densities are $1.50 \mathrm{~g} / \mathrm{cm}^{3}, 1.68 \mathrm{~g} / \mathrm{cm}^{3}, 1.71 \mathrm{~g} / \mathrm{cm}^{3}$ and $1.75 \mathrm{~g} / \mathrm{cm}^{3}$, respectively. The corresponding diameter shrinkages are $9.27 \%, 6.93 \%, 7.65 \%$ and $8.48 \%$. It is thus concluded that the apparent porosity, bulk density and linear shrinkage of the samples can be effectively controlled.

Tab. 2 shows the data of apparent porosity, density and diameter shrinkage of different samples. Fig. 8 and Tab. 2 show a special phenomenon that the diameter shrinkage of $\mathrm{Gp} 0$ calcined at $1070{ }^{\circ} \mathrm{C}$ for $3 \mathrm{~h}$ is similar to that of GP2, GP4 and GP6, but the apparent porosity of GP2, GP4 and GP6 is less than that of Gp0, and the bulk density of GP2, GP4 and GP6 is greater than that of Gp0.And this phenomenon also exists at $1180^{\circ} \mathrm{C}$. This is because the liquid phase formed by glass powder leads to the formation of closed pores, which leads to the deviation of test data. This confirmed the conclusion that SEM closed pore existed, and showed that glass powder had influence on pore structure. These changes may also affect the mechanical properties.

Tab. 2 Diameter shrinkage(D), apparent porosity(A) and density(d) of the samples.

\begin{tabular}{|c|c|c|c|c|c|c|c|c|c|}
\hline $\begin{array}{r}\text { Charac } \\
\text { ters }\end{array}$ & \multicolumn{3}{|c|}{1070} & \multicolumn{3}{|c|}{1130} & \multicolumn{3}{|c|}{1180} \\
\hline $\begin{array}{l}\text { Sampl } \\
\text { es }\end{array}$ & $\bar{D}$ & $\bar{A}$ & $\mathrm{~d}$ & $\bar{D}$ & $\bar{A}$ & d & $\bar{D}$ & $\bar{A}$ & d \\
\hline GP0 & 4.59 & 52.07 & 1.25 & 6.80 & 48.07 & 1.34 & 9.27 & 40.92 & 1.50 \\
\hline GP2 & 4.33 & 42.59 & 1.50 & 5.77 & 39.50 & 1.58 & 6.93 & 34.62 & 1.68 \\
\hline GP4 & 4.46 & 41.12 & 1.53 & 5.54 & 37.32 & 1.60 & 7.65 & 33.15 & 1.71 \\
\hline GP6 & 4.51 & 40.69 & 1.54 & 5.36 & 36.71 & 1.61 & 8.48 & 31.22 & 1.74 \\
\hline
\end{tabular}

\subsection{Pore structure}

Fig. 9 shows pore structure characteristics of GP4 calcined at different temperatures. As presented in Fig. $9 a$, the samples contain pores with diameters of $\sim 4 \mu \mathrm{m}$ and $\sim 10 \mu \mathrm{m}$, together with a few nanopores, which can be attributed to the fact that the slime and sawdust powder have different particle sizes. However, pore size distribution profiles of GP4 calcined at different temperatures are different. With increasing calcination temperature, the numbers of nanopore and $\sim 4 \mu \mathrm{m}$ pore are decreased, while that of $\sim 10 \mathrm{um}$ 
pore is increased. The diameter of the pores is increased as the calcination temperature is increased, due to the continuous densification of the samples.

As seen in Fig. $9 b, \sim 90 \%$ of the pores are less than $20 \mu \mathrm{m}$. The samples calcined at $1070^{\circ} \mathrm{C}, 1100^{\circ} \mathrm{Cand}$ $1130^{\circ} \mathrm{C}$ contain mainly pores of $<8 \mu \mathrm{m}$ and a small number of $8 \sim 20 \mu \mathrm{m}$ pores, with a ratio of 2:7. However, for the samples calcined at $1150^{\circ} \mathrm{C}$, the ratio is $7: 2$. Nanopores with sizes of up to $100 \mathrm{~nm}$ are found in the samples, with volume fraction of $<2 \%$. The difference in pore size and distribution would result in difference in mechanical properties. Closed pores may have positive effect on mechanical properties in some cases.

Fig. 10 shows the pore structure characteristics of samples calcined at $1180^{\circ} \mathrm{C}$ with different contents of glass powder. It can be seen the size and number of pores are similar with GP4 samples calcined at 1500 ${ }^{\circ} \mathrm{C}$. Fig. 10 shows pore structure characteristics of the samples calcined at $1180^{\circ} \mathrm{C}$ with different contents of glass powder. The size and number of pores are similar to those of GP4 calcined at $1500^{\circ} \mathrm{C}$. This means that the pore structure is not varied significantly if the calcination temperature is above $1150^{\circ} \mathrm{C}$. According to Fig. $5(h, I)$, mullite phase is continuously formed and the samples are densified as the calcination temperature is increased from $1130^{\circ} \mathrm{C}$ to $1180^{\circ} \mathrm{C}$. In the temperature range of $1150-1180^{\circ} \mathrm{C}$, the apparent porosity, bulk density and diameter shrinkage of the samples have almost unchanged, as illustrated in Fig. 8. Based on these results, it is further confirmed that the reaction has been complete at $1180^{\circ} \mathrm{C}$.

\subsection{Mechanical properties}

Fig. 11 shows flexural strength of the samples calcined at different temperatures. The flexural strength of GPO is increased from 2.70 MPa to $7.47 \mathrm{MPa}$, as the calcination temperature is increased from $1070^{\circ} \mathrm{C}$ to $1180^{\circ} \mathrm{C}^{[18]}$. The fracture strengths of GP2, GP4 and GP6 calcined at $1180^{\circ} \mathrm{C}$ for $3 \mathrm{~h}$ are $21.23 \mathrm{MPa}$, 25.27MPa and $28.36 \mathrm{MPa}$, respectively. This suggests that the reaction and densify are difficult at low temperatures due to the decomposition of organic matter. However, this problem can be readily solved by the addition of glass powder, owing to the formation of liquid phase to accelerate the reaction and densification.

Combining with SEM and pore structure analysis results, the flexural strength curves of GP2, GP4 and GP6 can be divided into two sections, $1070-1130^{\circ} \mathrm{C}$ and $1130-1180^{\circ} \mathrm{C}$. Over $1070-1130^{\circ} \mathrm{C}$, the flexural strength increases rapidly because of the promoting effect of the liquid phase derived from the glass powder. Over $1130-1180^{\circ} \mathrm{C}$, the increase in flexural strength is slow down. This observation is closely related to the formation of mullite and the variation in pore structure. In the high temperature regime, the number of $\sim 10 \mu \mathrm{m}$ pores is increased, while the number of $\sim 4 \mu \mathrm{m}$ pores is decreased.

Fig. 12 shows overall effects of calcination temperature and the content of glass powder on mechanical properties of the samples. It is found that the calcination temperature and glass powder have synergistic effect on the mechanical properties. Fig. 12 can be divided into three regions according to the effects of 
temperature and glass powder. In region I, the content of glass powder is less than $2 \%$. The mechanical properties are increased with increasing content of glass powder. This phenomenon is more pronounced at high temperatures. The calcination temperature has relatively weak effect on flexural strength. In region II, the content of glass powder is $>2 \%$, while the calcination temperature is in the range of $1070-$ $1150^{\circ} \mathrm{C}$. In this case, the flexural strength is dependent on both the calcination temperature and the content of glass powder. In region III, the effects of the content of glass powder and the calcination temperature are weakened.

\section{Conclusions}

Porous ceramics were successfully prepared by using solid state reaction method. The flexural strength of the samples was improved due to the addition of glass powder, due to the promoted formation of mullite and inhibited formation of kyanite. $4 \%$ glass powder is the optimal content, leading to the highest mullite content of $75.80 \%$ after calcining at $1180^{\circ} \mathrm{C}$, corresponding to a flexural strength of $28.36 \mathrm{MPa}$. Higher content of glass powder results in more quartz. Specifically, the sample calcined at $1180^{\circ} \mathrm{C}$ exhibits an apparent porosity of more than $31.22 \%$, while the diameter shrinkage is less than $8.48 \%$, which is suitable for production. This achievement has potential economic benefits and practical values in terms of the utilization of solid wastes.

\section{Declarations}

\section{Acknowledgements}

This work was supported by the Science and Technology Project of Anhui Province (1604a0802122 and 17030901091), the Academic Funding Project for the Top Talents of Colleges and Universities (No. gxbjZD14), Key Laboratory for Advanced Technology in Environmental Protection of Jiangsu Province (JH201840),Anhui University of science and technology 2019 Postgraduate Innovation Fund Project (2019cx2054) and National College Students Innovation and Entrepreneurship Training Program (2019103610).

\section{References}

[1] Niu X, Guo S, Gao L, et al. The mercury release during thermal treatment of two coal gangues and two coal slimes under N2 and air. Energ Fuel 2017,8648-8654.

[2] Li M, Zhang J, Huang Y, et al. Effects of particle size of crushed gangue backfill materials on surface subsidence and its application under buildings. Environ Earth Sci 2017,76:603-614.

[3] Jelínek P, Marschalko M, Lamich D, et al. Monitoring and analysis of burning in coal tailing dumps: a case study from the Czech Republic. Environ Earth Sci 2015,73:6601-6612. 
[4] Liu H,Liu Z. Recycling utilization patterns of coal mining waste in China. Resour Conserv Recy 2010,54:1331-1340.

[5] Chao X U,Kang X. Harm and Comprehensive Utilization of Coal Gangue. Environ Sci Techno 2010,102-104.

[6] Qing Z,Guoqiang Z. Treatment of Wastewater Containing Ni(II)by Pyrites in Coal Gangue. Environ Sci Techno 2008,37:104-105.

[7] Li Y, Yao Y, Liu X, et al. Improvement on pozzolanic reactivity of coal gangue by integrated thermal and chemical activation. Fuel 2013,109:527-533.

[8] Song Z, Jing C, Yao L, et al. Microwave drying performance of single-particle coal slime and energy consumption analyses. Fuel Process Technol 2016,143:69-78.

[9] Zhou K, Lin Q, Hu H, et al. The ignition characteristics and combustion processes of the single coal slime particle under different hot-coflow conditions in N2/O2 atmosphere. Energy 2016,136:173-184.

[10] Wang H, Liu S, Wang X, et al. Ignition and Combustion Behavior of Coal Slime in Air. Energ Fuel 2017,31:11439-11447.

[11] Medvedovski,Eugene. Alumina-mullite ceramics for structural applications. Ceram Int 2006,32:369375 .

[12] Zhang $H$, Zhang $Y$, Wang $B$, et al. Preparation and characterization of continuous alumina based fiber reinforced with orientated mullite whisker.2015,268:109-115.

[13] Gui K, Liu F, Wang G, et al. Microstructural evolution and performance of carbon fiber-toughened ZrB2 ceramics with SiC or ZrSi2 additive. J Adv Ceram 2018,7:343-351.

[14] Boussois K, Tessier-Doyen N,Blanchart P. Anisotropic kinetic of the kaolinite to mullite reaction sequence in multilayer ceramics. J Eur Ceram Soc 2013,33.243-249.

[15] De Aza A H, Turrillas X, Rodriguez M A, et al. Time-resolved powder neutron diffraction study of the phase transformation sequence of kaolinite to mullite. J Eur Ceram Soc 2014,34:1409-1421.

[16] Dong Y, Feng X, Feng X, et al. Preparation of low-cost mullite ceramics from natural bauxite and industrial waste fly ash. J Alloy Compd 2008,460:599-606.

[17] Hua K, Shui A, Xu L, et al. Fabrication and characterization of anorthite-mullite-corundum porous ceramics from construction waste. Ceram Int 2016,42:6080-6087.

[18] Guo H S, Li W F,Ye F B. Low-cost porous mullite ceramic membrane supports fabricated from kyanite by casting and reaction sintering. Ceram Int 2016,42:4819-4826. 
[19] Xu L, Xi X, Zhu W, et al. Investigation on the influence factors for preparing mullite-whisker-structured porous ceramic. J Alloy Compd 2015,649:739-745.

[20] Zhu Z W, Wei Z L, Shen J X, et al. Fabrication and catalytic growth mechanism of mullite ceramic whiskers using molybdenum oxide as catalyst. Ceram Int 2017,43.2871-2875.

[21] Lang Y, Zhao L, Dai X, et al. Effect of alumina fiber content on pore structure and properties of porous ceramics. Int J App/ Ceram Tec 2019, 16:814-819.

[22] Wang $Z$, Feng $P Z$, Wang $X \mathrm{H}$, et al. Fabrication and properties of freeze-cast mullite foams derived from coal-series kaolin. Ceram Int 2016,42:12414-12421.

[23] Yan S, Pan Y M, Wang L, et al. Synthesis of low-cost porous ceramic microspheres from waste gangue for dye adsorption. J Adv Ceram 2018,7:30-40.

[24] Gröttrup J, Schütt F, Smazna D, et al. Porous ceramics based on hybrid inorganic tetrapodal networks for efficient photocatalysis and water purification. Ceram Int 2017,43:14915-14922.

[25] Lu Q, Dong X, Zhu Z, et al. Environment-oriented low-cost porous mullite ceramic membrane supports fabricated from coal gangue and bauxite. J Hazard Mater 2014,273:136-145.

[26] Serra M F, Conconi M S, Gauna M R, et al. Mullite (3Al203-2SiO2) ceramics obtained by reaction sintering of rice husk ash and alumina, phase evolution, sintering and microstructure. $J$ Asian Ceram Soc 2018,4:61-67.

[27] Wang $\mathrm{Y}$, Cheng $\mathrm{H}$, Liu $\mathrm{H}$, et al. Effects of sintering temperature on mechanical properties of 3D mullite fiber (ALF FB3) reinforced mullite composites. Ceram Int 2013,39:9229-9235.

[28] Zhu Z W, Wei Z L, Sun W P, et al. Cost-effective utilization of mineral-based raw materials for preparation of porous mullite ceramic membranes via in-situ reaction method. Apple Clay Sci 2016,120:135-141.

[29] Liu P-F, Li Z, Xiao P, et al. Microstructure and mechanical properties of in-situ grown mullite toughened 3Y-TZP zirconia ceramics fabricated by gelcasting. Ceram Int 2018,44:1394-1403.

[30] Xu X H, Lao X B, Wu J F, et al. In-situ synthesis of SiCW/Al2O3 composite honeycomb ceramics by aluminium-assisted carbothermal reduction of coal series kaolin. Apple Clay Sci 2016,126:122-131.

[31] Dong Y, Zhou J, Lin B, et al. Reaction-sintered porous mineral-based mullite ceramic membrane supports made from recycled materials. $J$ Hazard Mater 2009, 172:180-186.

[32] Jing Q, Bao J, Ruan F, et al. The effect of YF3 on the mechanical properties and low-temperature degradation of 3Y-TZP ceramics. Ceram Int 2019,45.24212-24220. 
[33] Guo H,Li W. Effects of Al2O3 crystal types on morphologies, formation mechanisms of mullite and properties of porous mullite ceramics based on kyanite. J Eur Ceram Soc 2018,38:679-686.

[34] Deutou J G N, Mohamed H, Nzeukou N A, et al. The role of kyanite in the improvement in the crystallization and densification of the high strength mullite matrix Phase evolution and sintering behaviour. J Therml Anal Calorim 2016,126:1211-1222.

\section{Figures}

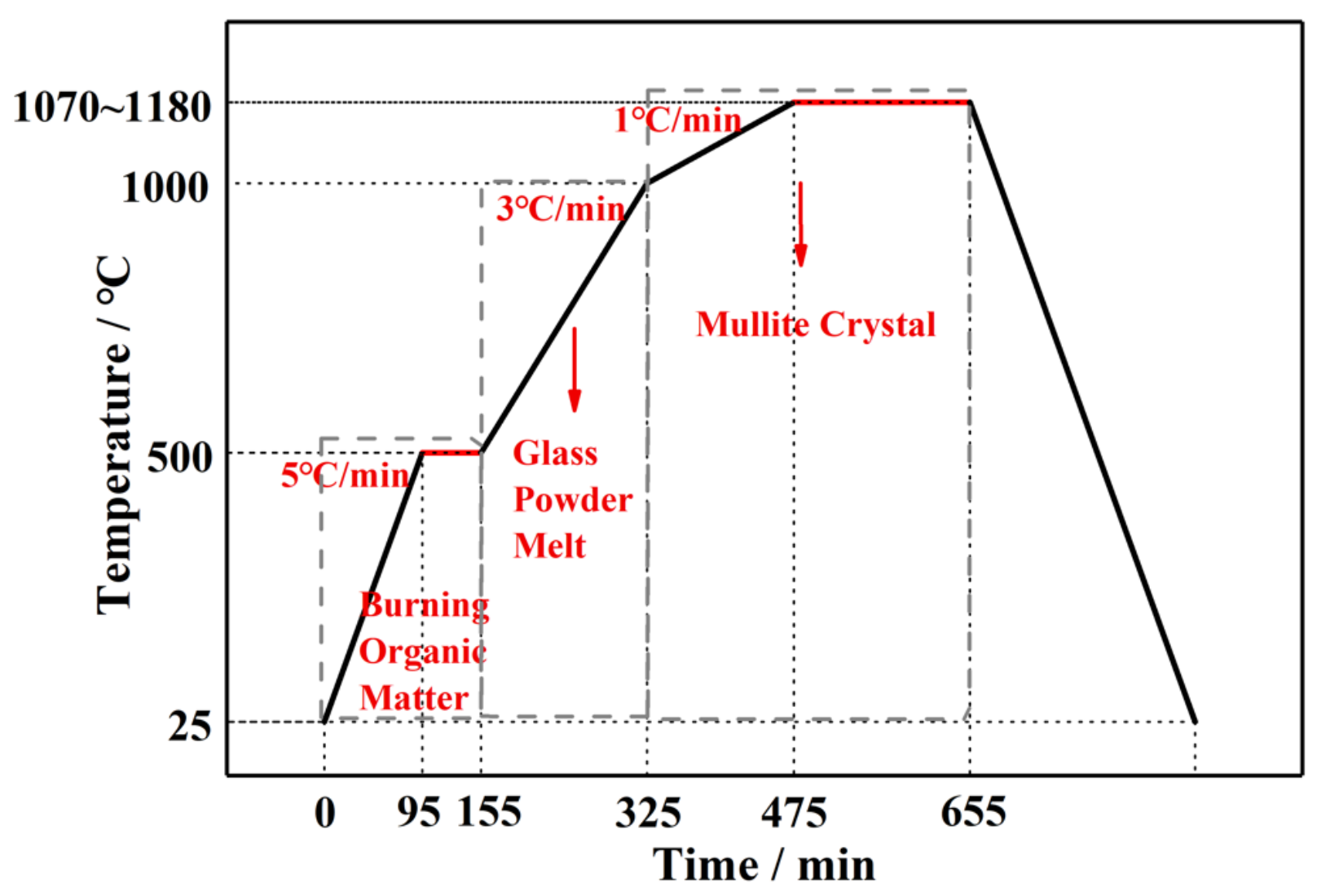

Figure 1

Temperature profile to calcine the samples. 


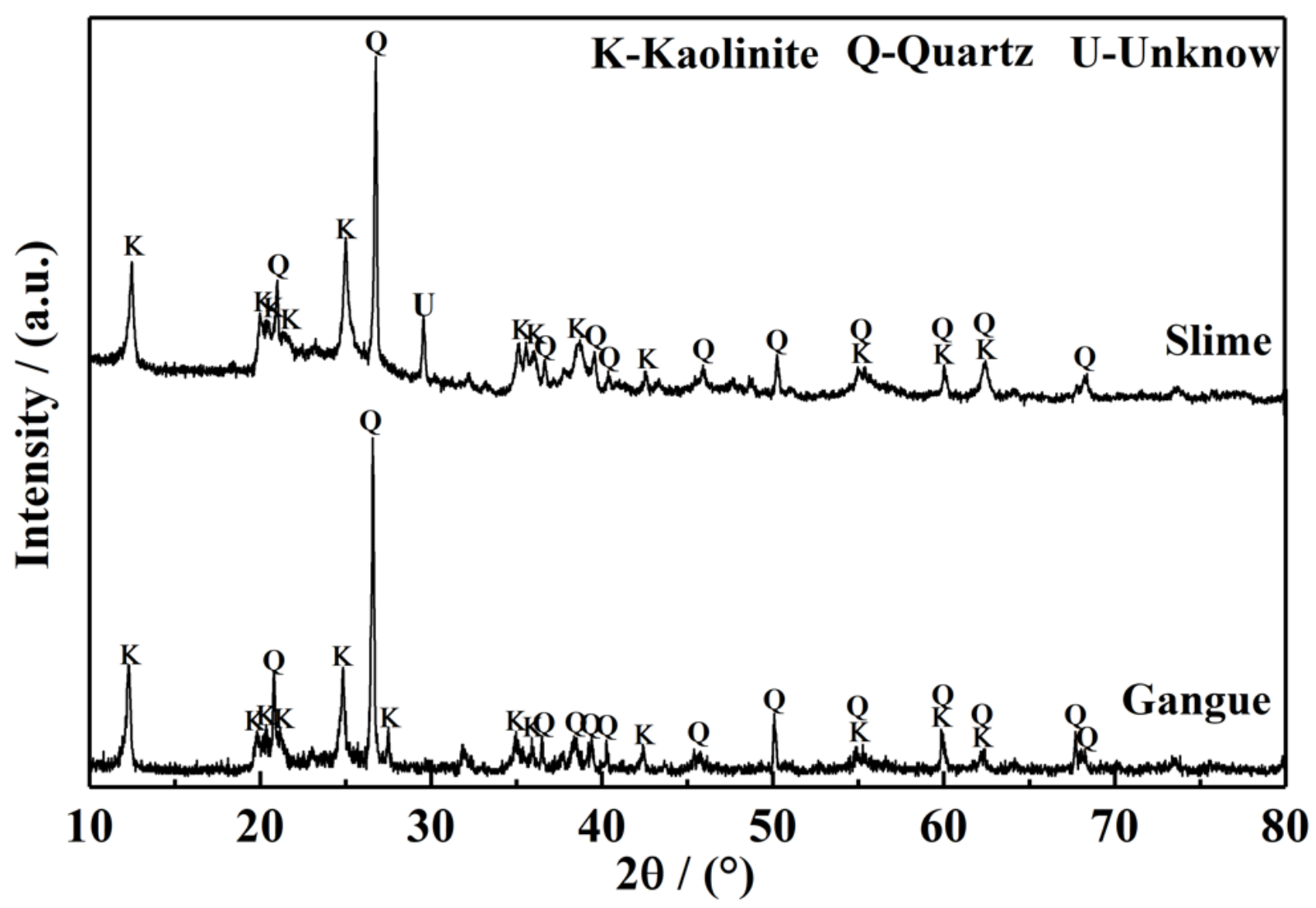

Figure 2

XRD patterns of the raw materials.
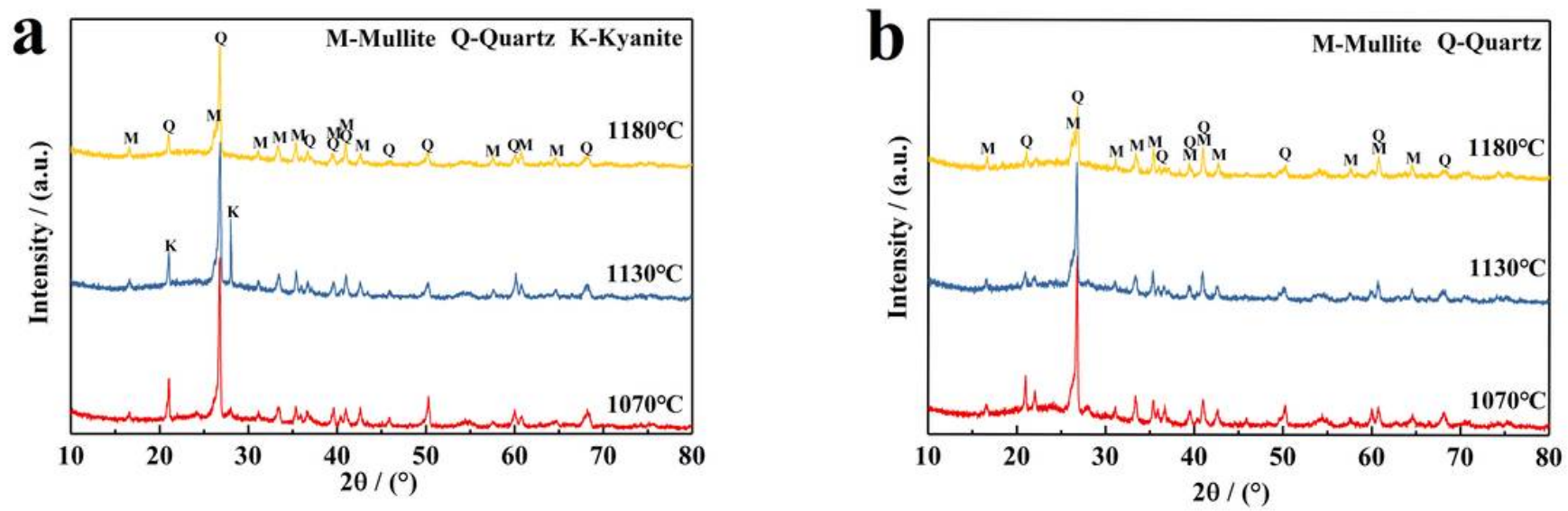

Figure 3

XRD patterns of selected samples calcined at different temperatures: (a) GP0 and (b) GP4. 

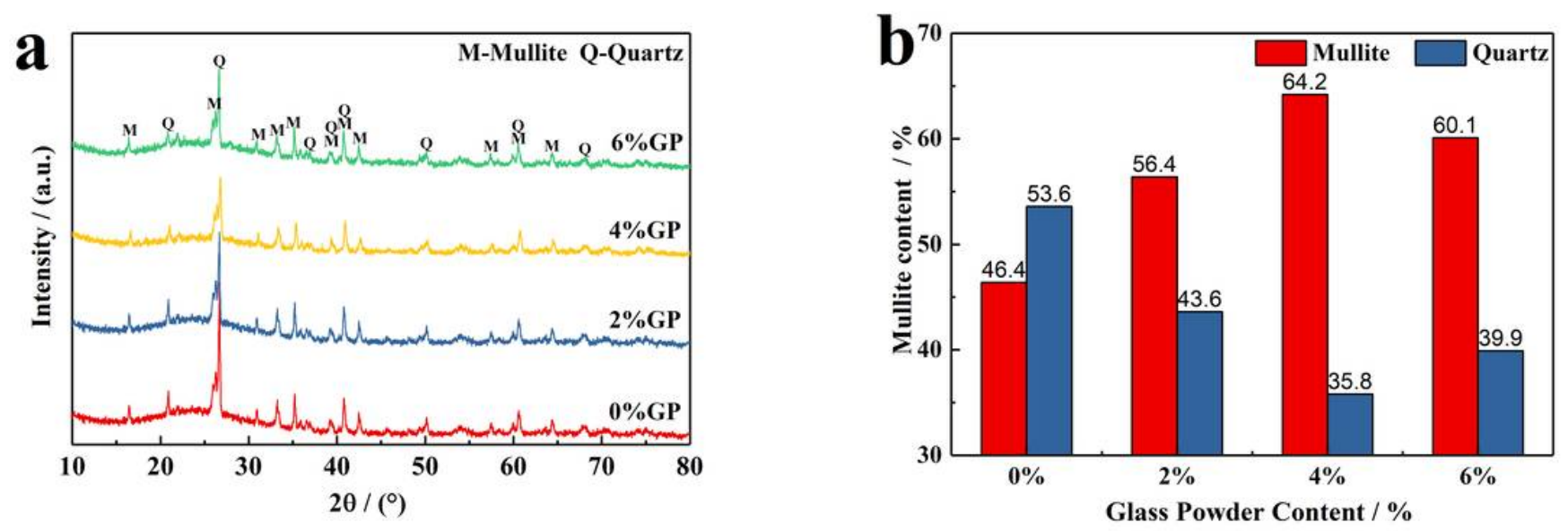

\section{Figure 4}

XRD patterns and phase contents of the samples with different contents of glass powder after calcining at $1180^{\circ} \mathrm{C}$ for $3 \mathrm{~h}$.

2

\section{Figure 5}

SEM of representative samples: (a, d) GP0 $1070^{\circ} \mathrm{C}$, (b, e) GP0 $1130^{\circ} \mathrm{C},(\mathrm{c}, \mathrm{f}) \mathrm{GPO} 1180^{\circ} \mathrm{C}$, (g) GP4 $1070^{\circ} \mathrm{C}$, (h) GP4 $1130^{\circ} \mathrm{C}$ and (i) GP4 $1180^{\circ} \mathrm{C}$. 


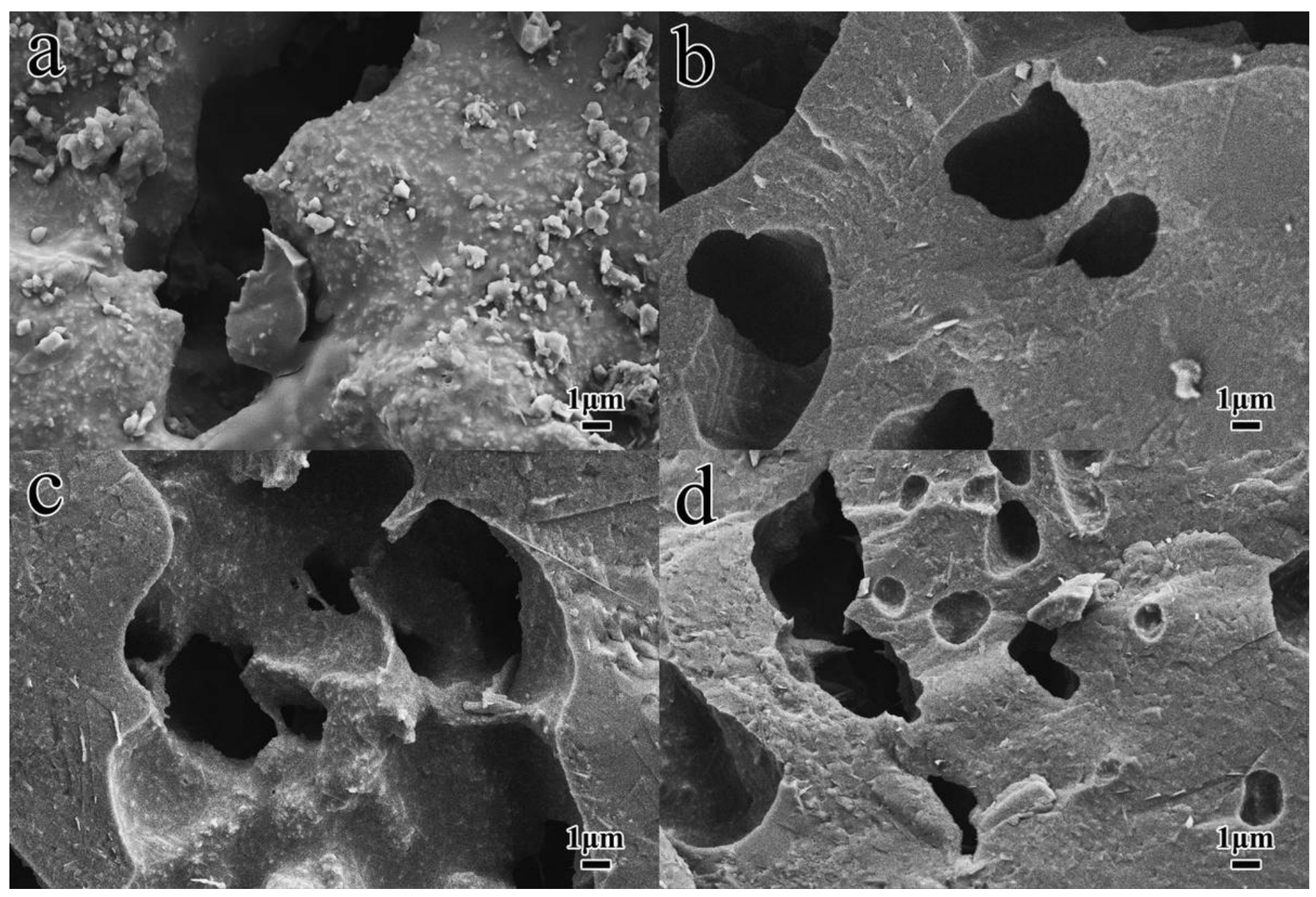

Figure 6

Cross-sectional SEM images of the samples calcined at $1180^{\circ} \mathrm{C}$ for $3 \mathrm{~h}:$ (a)GP0, (b)GP2, (c)GP4 and (d)GP6. 


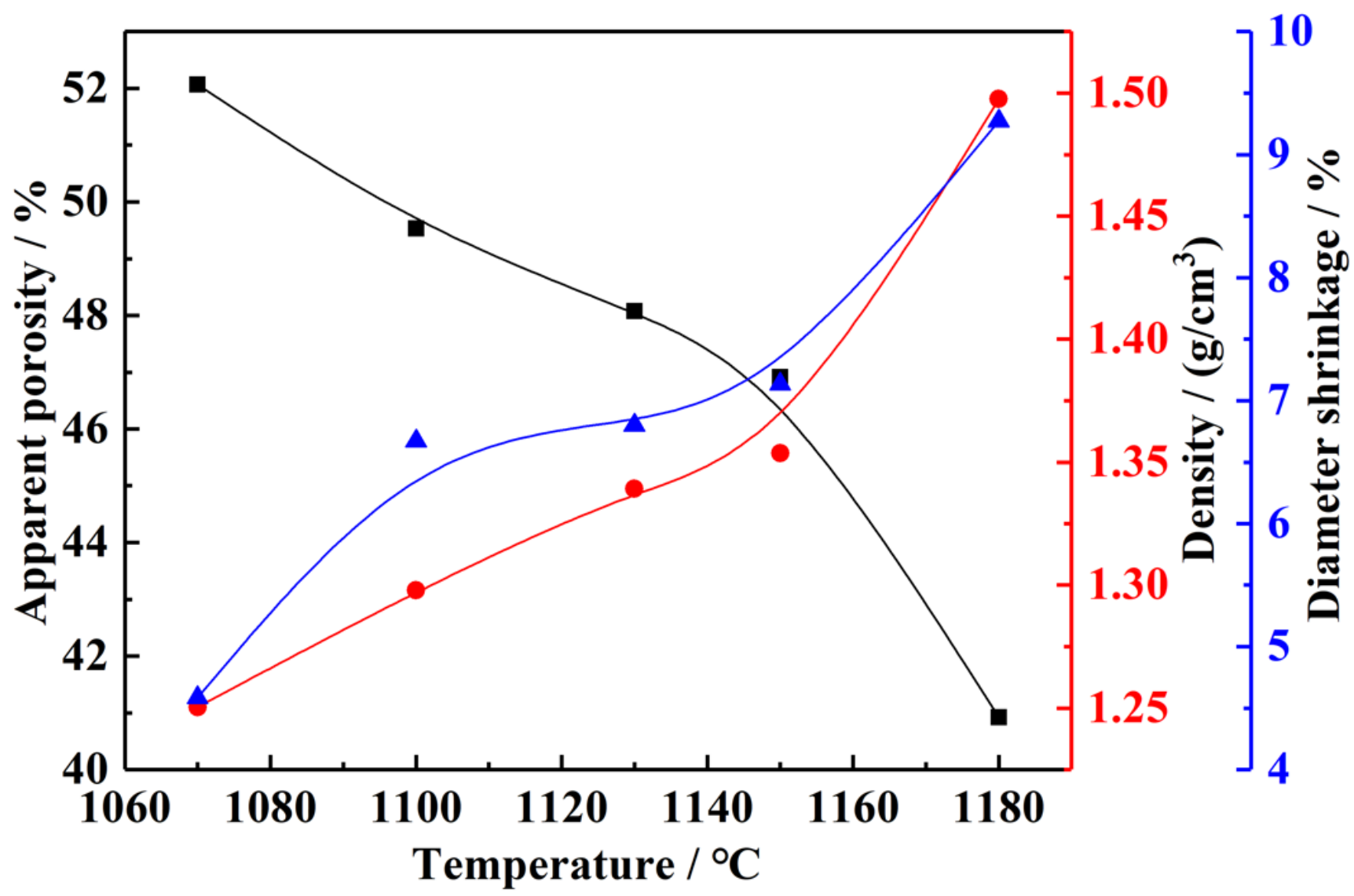

Figure 7

Apparent porosity, density and diameter shrinkage of GPO with calcination temperature. 

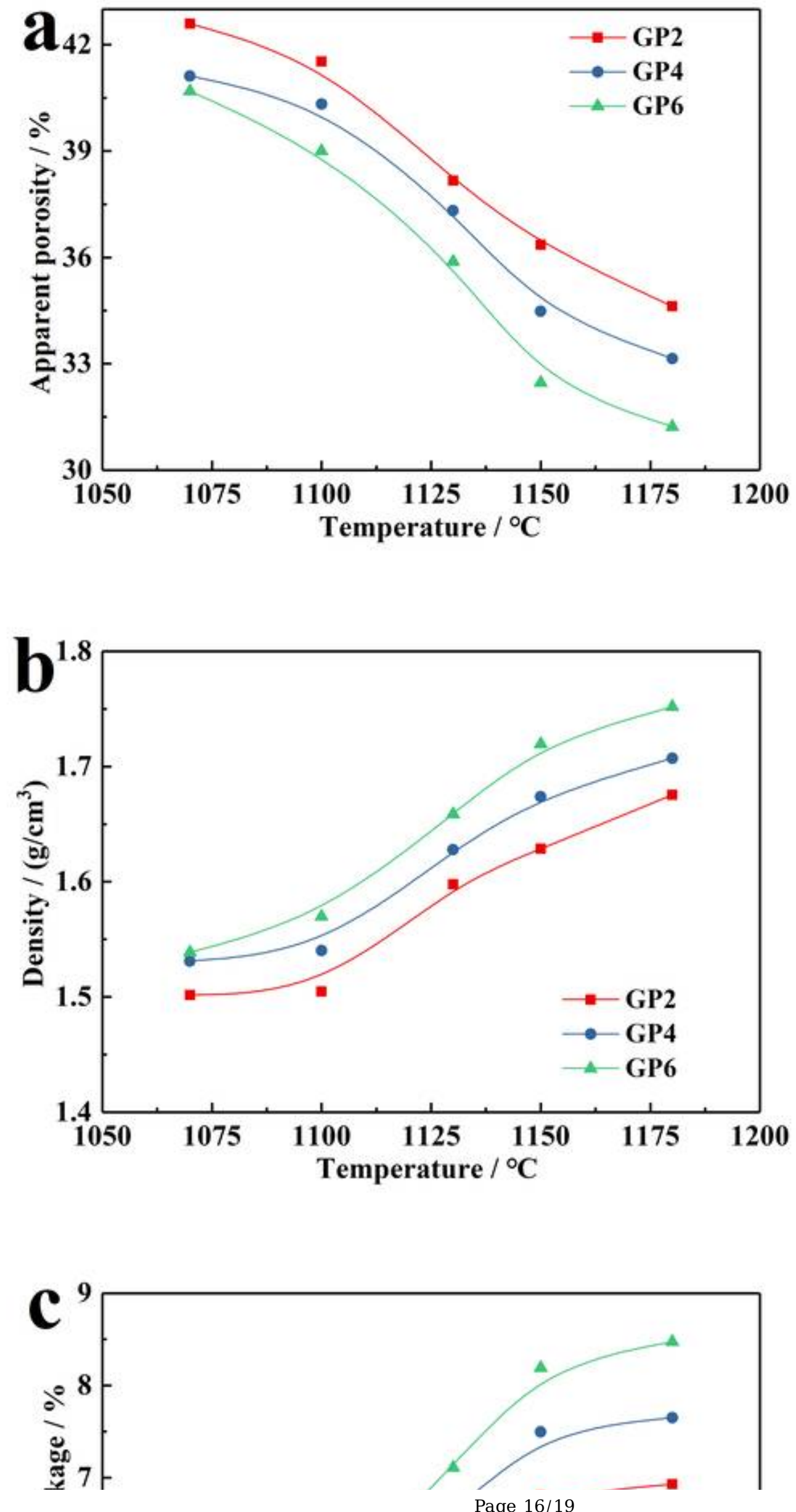


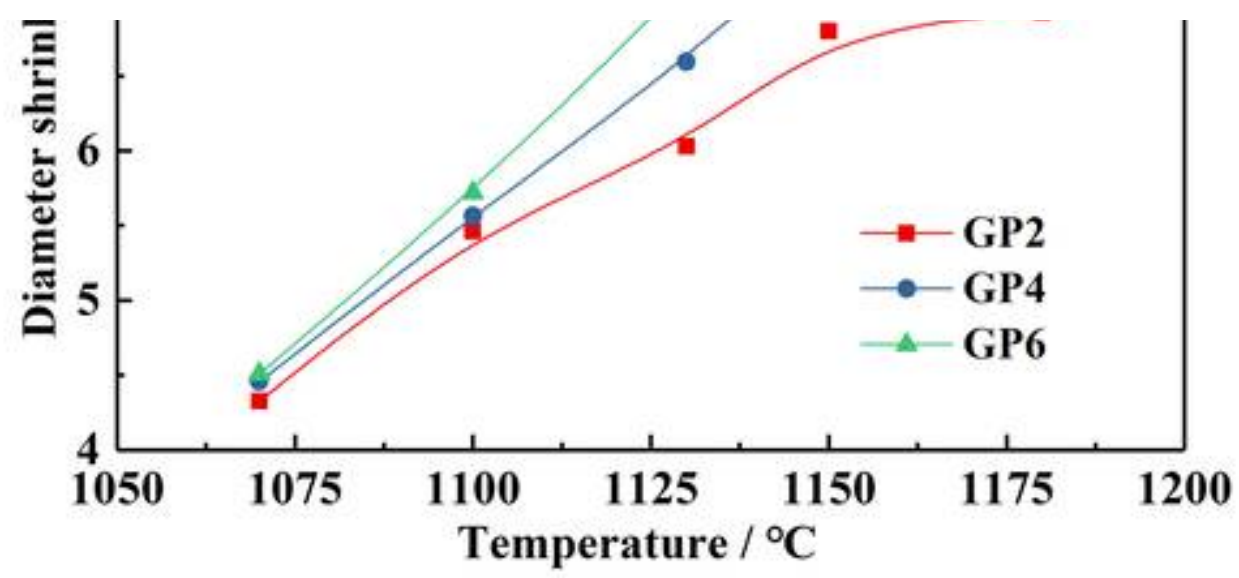

Figure 8

Apparent porosity(a), density(b) and linear shrinkage(c) of GP2, GP4, GP6 with calcination temperature.
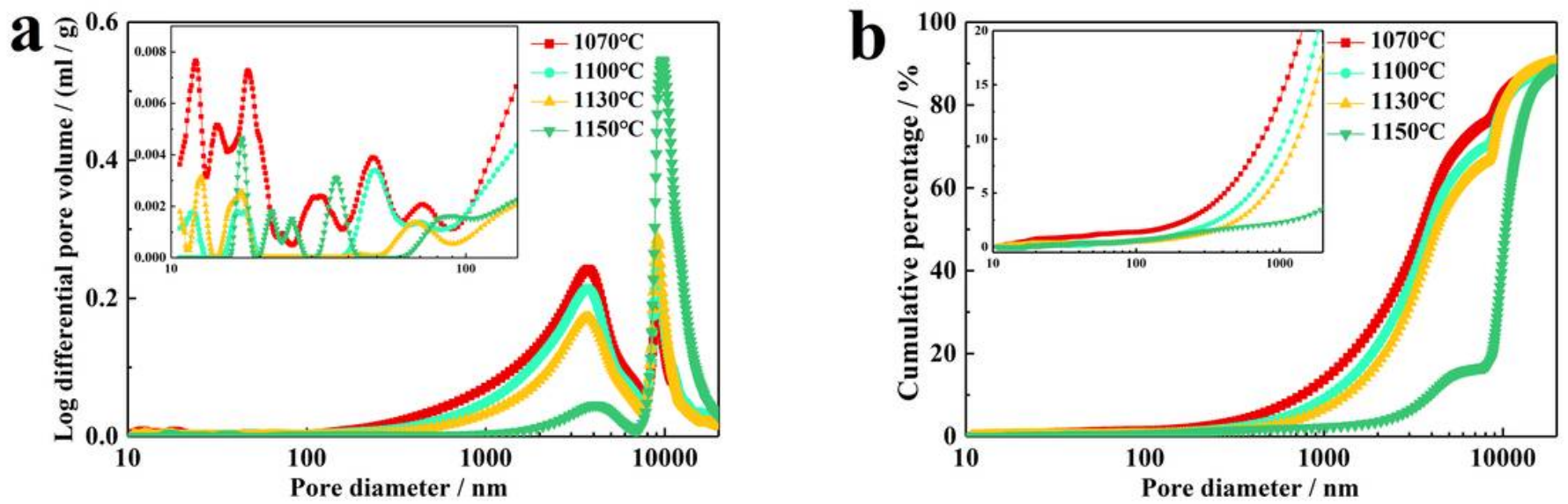

Figure 9

Pore structure characteristics of GP4 calcined at different temperatures. 

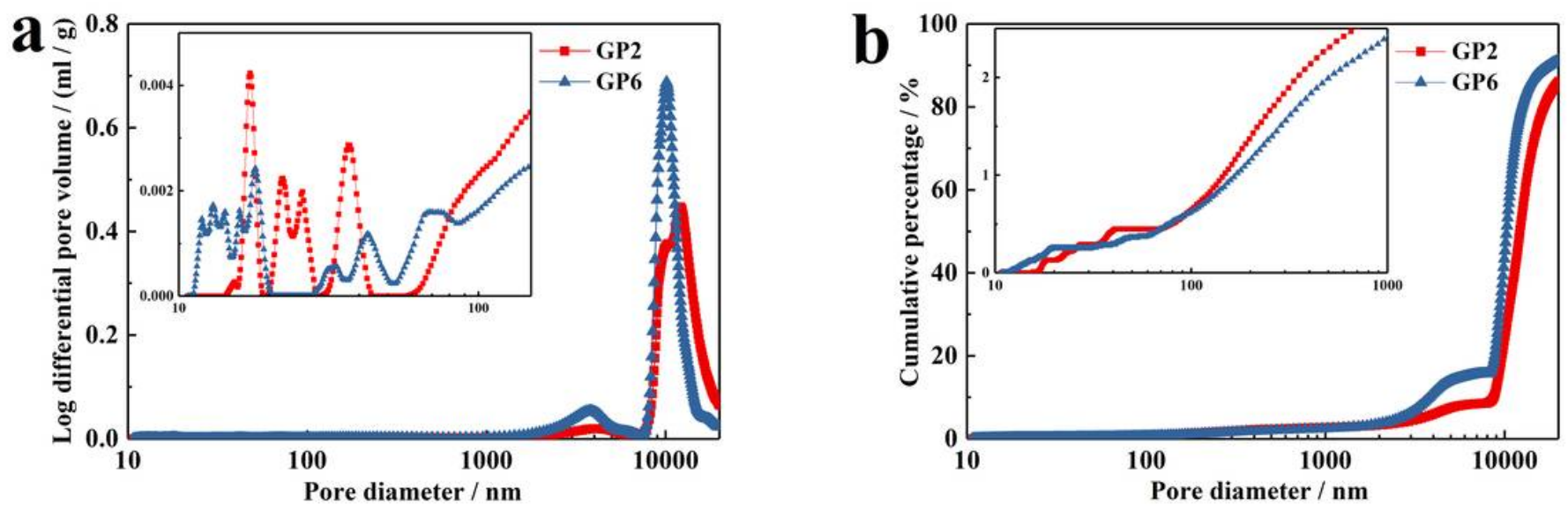

Figure 10

Pore structure characteristics of the samples calcined at $1180^{\circ} \mathrm{C}$ with different contents of glass powder.

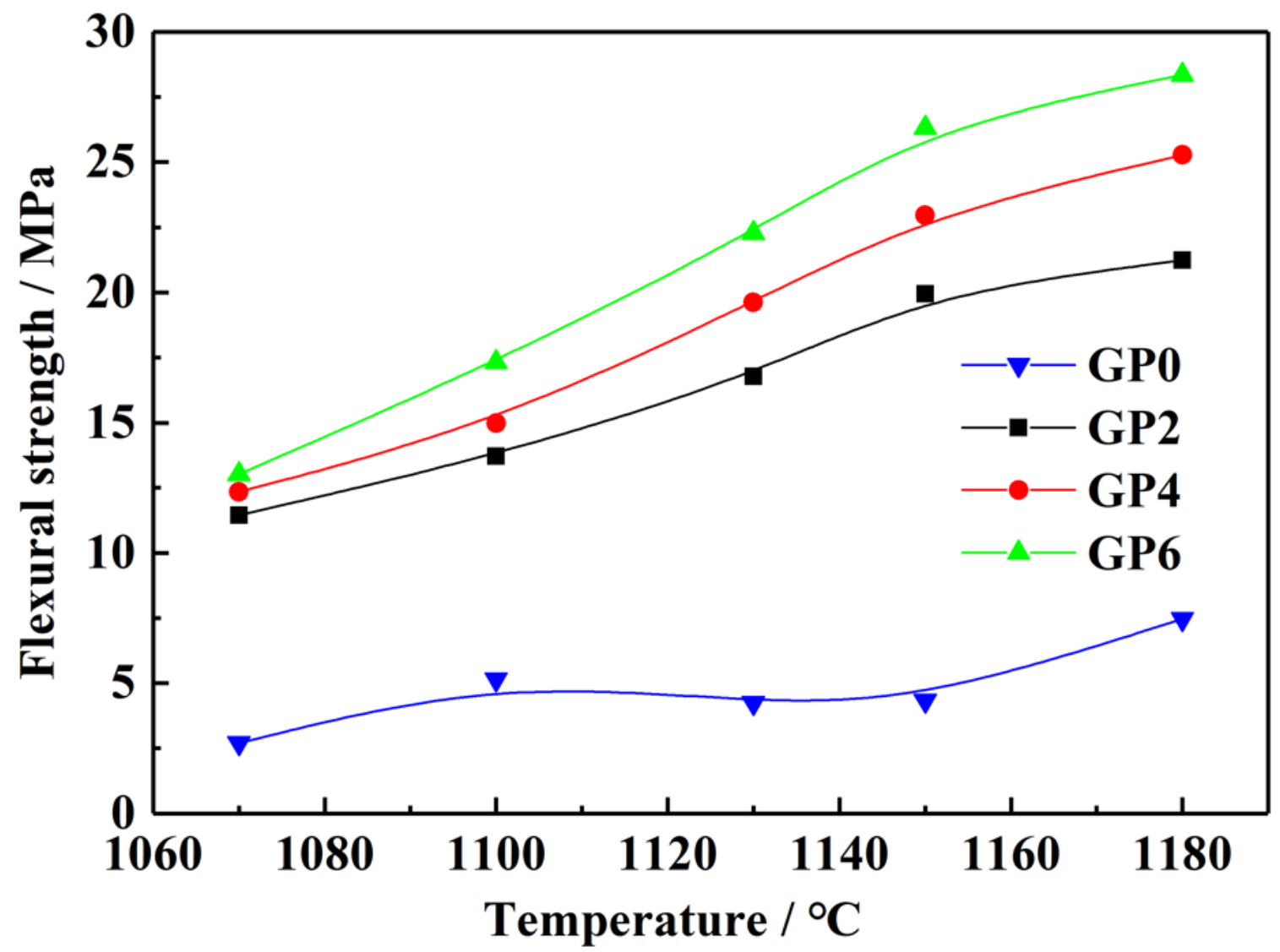

Figure 11

Flexural strength of the samples with calcination temperature. 


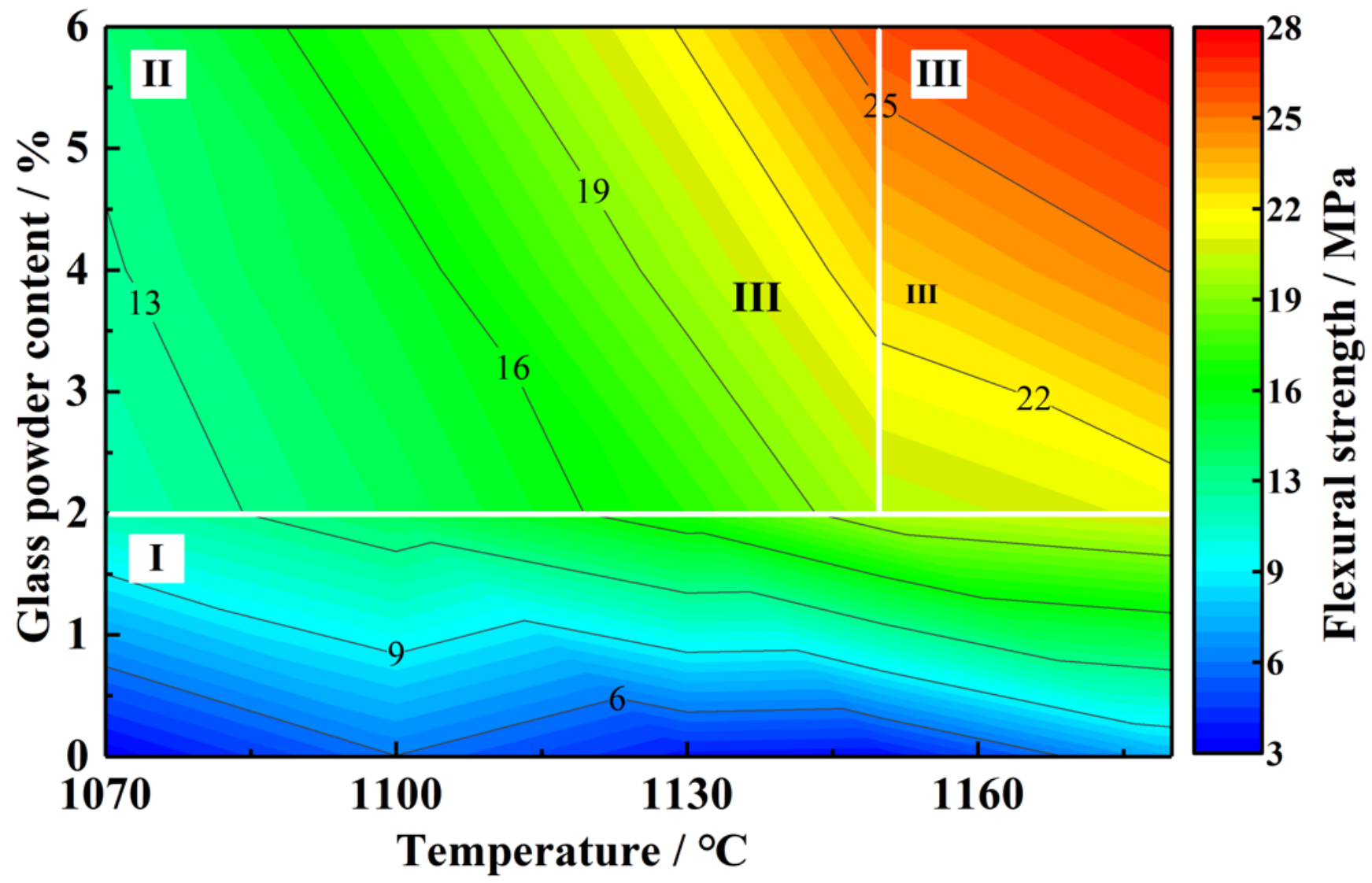

Figure 12

Effects of calcination temperature and content of glass powder on flexural strength of the samples. 